\title{
Continuous production of a multi-filament reinforced metal matrix composite strip from the semisolid state
}

\author{
Antonio de Pádua Lima Filho ${ }^{1, a}$, Rafael Shoiti lkeda ${ }^{2, b}$, \\ Tales Paschoalino de Castro ${ }^{3, c}$ and Ricardo Luiz Pugina Filho ${ }^{4, d}$ \\ 1,2,3,4 Unesp-São Paulo State University-Department of Mechanical Engineering \\ Ilha Solteira-SP, № 56, Brazil, CEP. 15385-000

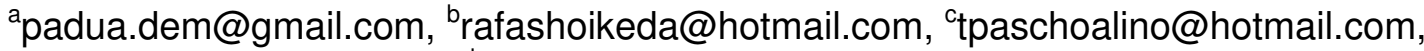 \\ dricardo_pugina@hotmail.com
}

Keywords: Metal matrix composites; Metallic fibres; Strip casting; SnPb alloys

\begin{abstract}
Continuous metal matrix composite strip casting (MMCS-ing) composed of six 0.3-mm diameter annealed bare copper wires in a eutectic $\mathrm{SnPb}$ matrix was manufactured by a two-roll melt dragged processing (TRMD-ing) method at a rate of $0.3 \mathrm{~m} / \mathrm{s}$. The wires were dragged through a semisolid pool with a fibre contact time of approximately $0.2 \mathrm{~s}$. The required gap between rolls to thixoforge the semisolid material around the wire filaments was approximately $1.4 \mathrm{~mm}$. A successful continuous composite strip casting was achieved with a notably good degree of wire alignment. No cracks were observed at the copper wire/matrix interface. However, regions of porosity occurred in the matrix; their possible formation mechanisms are discussed. The solidification structure of the matrix was analysed, and the analysis results indicated the formation of small globular grains measuring approximately $3 \mu \mathrm{m}$ in diameter. The specimens were evaluated for their tensile properties and compared with the rule of mixtures. The surface fracture analysis indicated a good matrix/fibre union. MMCS-ing is an economically viable process and has significant advantages over other metal matrix composite (MMC) fabrication methods.
\end{abstract}

\section{Introduction}

Two-roll melt drag processing (TRMD-ing) is a new technology used to perform continuous strip metal matrix composite casting (MMCS-ing) from the semisolid [1-3]. Using such processing, composite strips are obtained in the horizontal plane of the apparatus, and the processing includes a cooling slope for feeding the semisolid material [4]. In this process, the reactions at the interfaces between the matrix and fibres are minimised by the short contact time with the semisolid state (approximately $0.2 \mathrm{~s}$ ) compared with traditional processing that uses, for example, squeeze casting [1-3]. Furthermore, the advantages are the following: longer strip metal matrix composites, shorter production times, potentially cheaper and good alignment of the fibre within the matrix. Damage to the fibres is naturally minimised because the pressing is made in the semisolid state [1-3].

Using TRMD-ing to produce metal matrix composites tends to result in fine microstructures, e.g., approximately $3 \mu \mathrm{m}$ in size [3], and generates a relatively low separation force between rolls because the matrix material in the slurry/mush state has a lower yield stress than in the solid state. For this reason, non-rigid rolls, with the consequent reduced energy consumption, can be used. In addition, this process suggests that composites with low matrix plasticity can be produced, which is otherwise difficult to achieve from the solid state.

In the TRMD-ing method, two solidification layers between rolls have to meet the fibres to be thixopressed [3]. No push force is necessary to extract the MMCS-ing from the stand mill [3]. The main processing parameters that must be controlled to ensure the production of the metal matrix composite with good quality are: roll speed, alloy pouring temperature, lower roll temperature and position of formation of the fibre/metallic puddle at the rolls [1-3]. Composites of good quality are those for which the inserted fibres are fully coated by the matrix. This process minimises interfacial reactions and protects the fibre from degradation and is essential for transmitting the loading to the reinforcement. 
The product is a metal matrix composite with the fibre aligned, inserted and embedded in the metallic matrix [1-3]. However, cracks were observed running along the fibre/matrix interface [3]. These cracks were attributed to the work hardening of the metallic fibre (stainless steel 316L of 0.3$\mathrm{mm}$ diameter) with the low flexibility required during the matrix solidification/pressing. This behaviour suggests that cracks will not form at the reinforcement/matrix interface using fibres with higher compliance. Hence, composites of high performance can be achieved.

In this work, a slag weir is used to guide the fibres (six copper wires of $0.3-\mathrm{mm}$ diameter) linearly. This slag weir is placed within the nozzle at the lower roll (solidification roll). The upper roll thixoforges the semisolid material, which is transported by the chill shell that nucleated on the lower roll. The semisolid $\mathrm{SnPb}$ eutectic alloy was chosen as a metallic matrix for its promotion of the formation of a continuous strip, its easily identifiable phase and its manipulability for experimental study [5]. The sequences required to perform the experimental procedure in this work are shown. The insertion of multi-filament fibre has not previously been reported using this method. After TRMD-ing, the specimens were tensile tested to verify the quality of the reinforcement/matrix interface. This testing was followed by scanning electron microscopy (SEM) fractograph surface analysis.

Significantly, the processing developed in this work can be applied to the continuous casting of composite strips of various reinforcement/metallic matrix combinations, practically eliminating fibre/matrix interfacial products and thus resulting in composites of high performance. TRMD-ing can be observed in <https://www.youtube.com/watch? $\mathrm{v}=\mathrm{tTUb} 4 \mathrm{Fw}$ VhPU\&feature=youtu.be>, accessed: on 27 December 2013.

\section{Experimental Set Up and Procedure Stand Mill Set Up for TRMD-ing}

A stand mill was modified and instrumented to obtain continuous metal matrix composites directly from liquid passing to the semisolid state. This apparatus utilised a cooling slope fitted with three 3-mm diameter K-type thermocouples, as shown in Fig. 1. The cooling slope produces the semisolid material that feeds the nozzle at the lower roll. The nozzle and the lower roll are also instrumented with 3-mm diameter K-type thermocouples. The cooling slope with inclination of $21^{\circ}$ is made of mild steel in a " $v$ " shape with a hole at the end to allow the semisolid material to feed the nozzle.

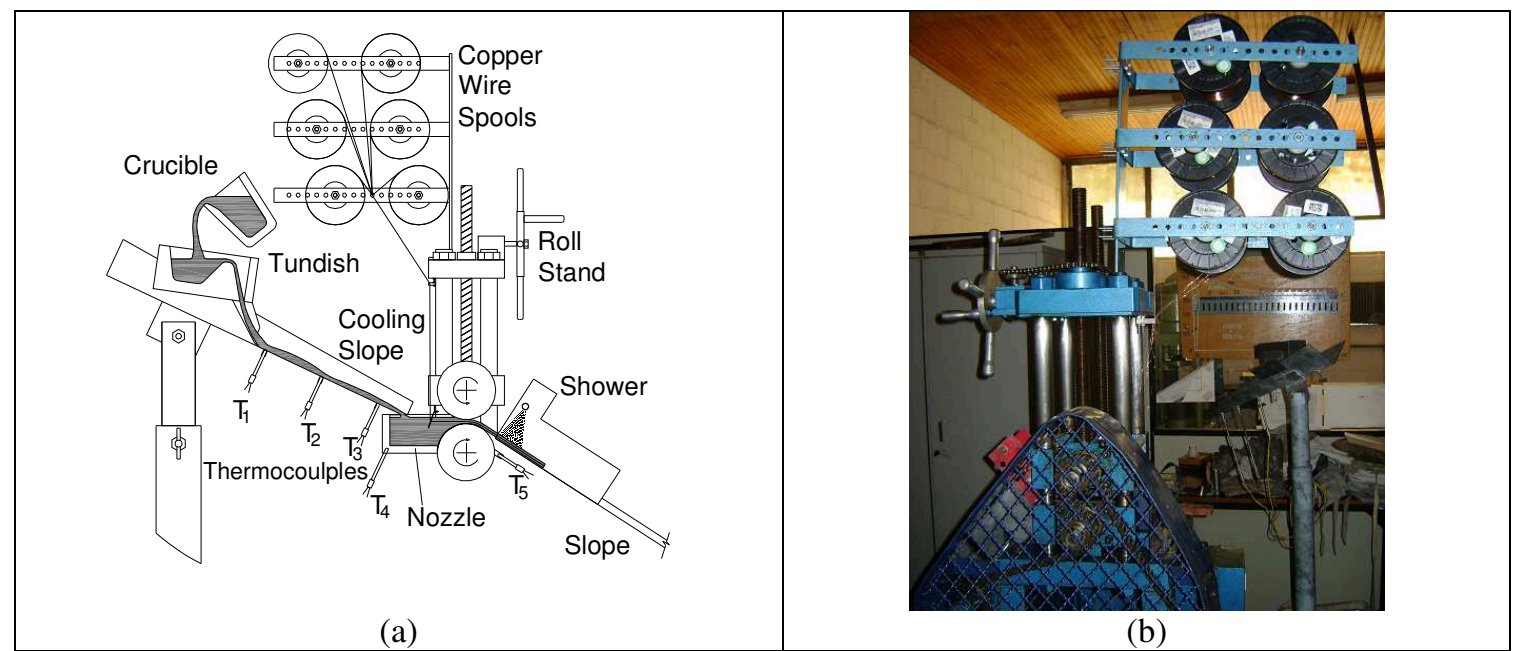

Fig. 1 Set-up for the preparation of the metal matrix composite strip casting for multifilament processing (a) and (b). Thermocouples ( $\mathrm{T}_{1}, \mathrm{~T}_{2}, \mathrm{~T}_{3}, \mathrm{~T}_{4}$ and $\left.\mathrm{T}_{5}\right)$.

The nozzle is preheated to avoid pre-solidification of the semisolid material and thus maintain the gauge width profile. A good nozzle/lower roll interface avoids leakage during operation. The nozzle has a volume of approximately $100 \mathrm{ml}$, a width of $45 \mathrm{~mm}$ and $81 \mathrm{~mm}$ at bottom and top, respectively, and a height of $55 \mathrm{~mm}$. The arc of the contact with the nozzle pool surface is 
approximately $50 \mathrm{~mm}\left(\alpha_{1}=60^{\circ}\right)$, and the distance from here to the exit of the stand mill is $63 \mathrm{~mm}$ $\left(\alpha_{2}=69^{\circ}\right)$.

The semisolid material begins to solidify upon contact with the surface of the lower roll (solidification roll). The gap between the rolls can be adjusted by means of two housing screws acting upon the upper roll. The gap was adjusted to produce a metal matrix composite strip of approximately $1.4 \mathrm{~mm}$ in thickness. The roll speed was set to $15 \mathrm{~m} / \mathrm{min}$ because it has been previously shown to produce the best results $[3,5]$. The rolls are made of mild steel of $105 \mathrm{~mm}$ and $101 \mathrm{~mm}$ diameter and length, respectively. The rolls were ground with 1200 grade sandpaper. At the mill stand exit there is also a slope, where the metal matrix composite strip is rapidly cooled by a water shower to room temperature, as shown in Fig. 1.

\section{Matrix Preparation}

A $500 \mathrm{ml}$ crucible is first used to cast the $\mathrm{SnPb}$ eutetic matrix material in an electric furnace $(6600 \mathrm{~W} / 220 \mathrm{~V})$. The material is then poured into an 80-ml tundish at a flow rate of approximately $13 \mathrm{ml} / \mathrm{s}$, which then feeds out onto the cooling slope. The tundish acts as a static control. The pouring temperatures of approximately $270{ }^{\circ} \mathrm{C}, 280{ }^{\circ} \mathrm{C}$ and $290{ }^{\circ} \mathrm{C}$ were used for testing the quality of the composite strip casting. This temperature was measured with an immersion thermocouple in the crucible. The molten alloy runs a distance of approximately $300 \mathrm{~mm}$ along the cooling slope to produce the semisolid material.

\section{Wire Spool Guide}

Multi-filament wire, comprised of six 0.3-mm diameter bare copper wires (ASTM B1), was placed to obtain the composite, as shown in Figs. 2 (a) and (b). The wires from the six spools are passed through the slag weir made of stainless steel cloth with holes of approximately $1.0 \mathrm{~mm}$ in diameter and continue through the gap between the rolls to guide six $0.3-\mathrm{mm}$ diameter copper wires. The six wires are also pre-tensioned at the exit of the stand mill to maintain alignment.

The wires were fed from the spool at room temperature, without any cleaning, pre-heating or pre-coating. The wire guide system was tapered to facilitate the movement of the wires through the semisolid puddle. The insertion of the wires in the matrix can be varied; in addition, there is also the possibility of obtaining metal matrix composites with different mechanical and physical properties by variation of the reinforcement volume fraction. A round 10-mm diameter aluminium bar placed at the slag weir allowed a smooth movement of the six wires when pulled by the semisolid metallic puddle, Fig. 2 (b).

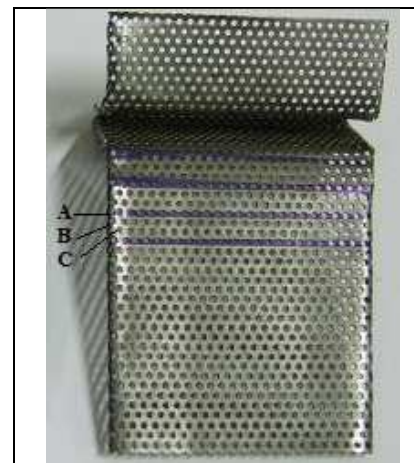

(a)

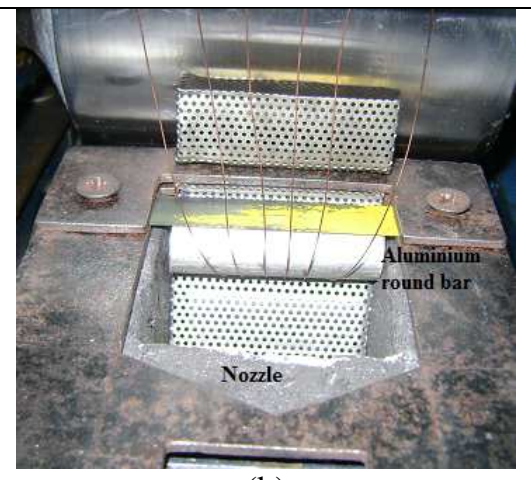

(b)

Fig. 2 Slag weir used to guide multifilament indicating the position tested in this work: "A", "B" and " $\mathrm{C}$ " selected for the best position to embed the wires.

\section{Optical and scanning electron microscope (SEM) examination}

The samples of the produced composite strips were sectioned and mounted in epoxy plugs for microscope examination. The sample was ground on 240 grit paper (at $150 \mathrm{rpm}$ ) to obtain a flat surface, then manually ground with 800 grit, 1000 grit and 1200 grit for approximately $2-3$ min, and finally and polished (with 6,3 and $1 \mu \mathrm{m}$ diamond paste for approximately 2 - 3 minutes). 
Ultrasonic cleaning was used between each step. The periods and pressure of polishing were controlled to minimise the inevitable relief between the matrix and the reinforcement.

Optical macroscopic analyses were performed on unetched samples to determine the quality of the composite and the reinforcement distribution in a prepared cross-sectional area of $30 \mathrm{~mm}^{2}$ using an Olympus SZ61 apparatus. The reinforcement volume fraction of approximately 1.4\%, was determined by dividing the total area of the six $0.3-\mathrm{mm}$ diameter copper wires by the area (approximately $30 \mathrm{~mm}^{2}$ ) of the tensile tested composite. The composite constituents were analysed using EDS in the SEM with an Oxford INCA system. The results were ZAF corrected, and pure metal standards used for $\mathrm{Fe}, \mathrm{Cr}, \mathrm{Ni}, \mathrm{Mo}, \mathrm{Cu}$ and $\mathrm{Sn}$. The compound standards of $\mathrm{CaCO}_{3}, \mathrm{SiO}_{2}$ and $\mathrm{PbF}_{2}$ were used for $\mathrm{C}, \mathrm{O}$ and $\mathrm{Pb}$ analysis, respectively.

\section{Mechanical testing}

Flat specimens for tensile testing were shear cut from the continuous strip composite using a guillotine. The dimensions are in agreement with the Standard Test Method for Tensile Properties of Fiber-Reinforced Metal Matrix Composites (ASTM D 3552 - 77). Fig. 3a shows samples prepared with tabs, and Fig. $3 \mathrm{~b}$ shows the dimensions of the parallel-sided specimens. The tabs, which reduce the peak specimen stress, were prepared to avoid penetration of the composite. Epoxy resin (trade name Araldite $24 \mathrm{~h}$ ) and a bench vice were used to attach the tabs. An MTS -810.25 apparatus with a maximum load scale of $25 \mathrm{kN}$ was used. The machine was set to stop the tensile test after achieving an elongation of $20 \mathrm{~mm}$ at a constant speed of $0.03 \mathrm{~mm} / \mathrm{s}$. A scanning electron microscope (SEM LEO 435 VPI) was used to examine the fracture mode in tensile tests.

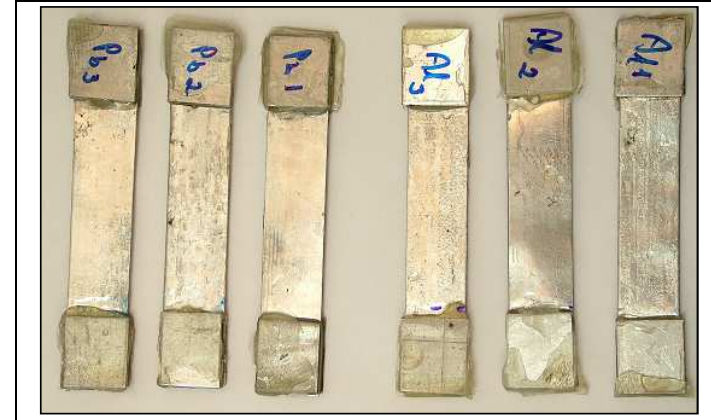

(a)

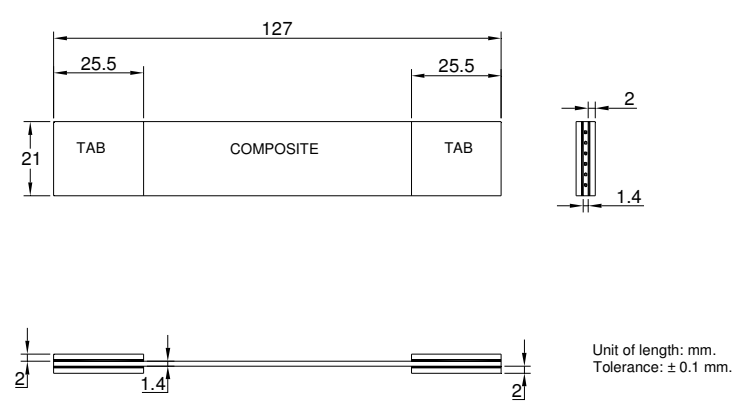

(b)

Fig. 3 Strip specimens for tensile testing from the six copper wires embedded in the $\mathrm{SnPb}$ metal matrix composite strip (a); and general dimensions (b).

\section{Results and Discussion}

\section{Formation, Surface Defects and Consolidation of the Composite Strip}

Three composite strips of $6 \mathrm{~m}$ in length, $49 \mathrm{~mm}$ in width, $1.4 \mathrm{~mm}$ in thickness and approximately $3.3 \mathrm{~kg}$ in weight were produced (Fig. 4 and Table 1 for dimensions). The strips were edge-trimmed to obtain a width of approximately $45 \mathrm{~mm}$.

Table 1. Dimensions of the continuous composite strips (six $0.3-\mathrm{mm}$ copper wires/SnPb eutectic matrix).

\begin{tabular}{|c|c|c|c|c|c|c|}
\hline \multirow{2}{*}{$\begin{array}{c}\text { Distance from the } \\
\text { head }\end{array}(\mathrm{m})$} & \multicolumn{3}{|c|}{ Thickness $(\mathrm{mm})$} & \multicolumn{3}{c|}{ Width (mm) } \\
\cline { 2 - 7 } & \multicolumn{3}{|c|}{ Pouring temperature } & \multicolumn{3}{c|}{ Pouring temperature } \\
\cline { 2 - 7 } & $\approx 270^{\circ} \mathrm{C}$ & $\approx 280^{\circ} \mathrm{C}$ & $\approx 290^{\circ} \mathrm{C}$ & $\approx 270^{\circ} \mathrm{C}$ & $\approx 280^{\circ} \mathrm{C}$ & $\approx 290{ }^{\circ} \mathrm{C}$ \\
\hline 1 & 1.4 & 1.3 & 1.4 & 48 & 46 & 48 \\
\hline 2 & 1.5 & 1.5 & 1.7 & 51 & 51 & 76 \\
\hline 3 & 1.3 & 1.4 & 1.6 & 56 & 49 & 79 \\
\hline 4 & 1.5 & 1.3 & 1.7 & 62 & 53 & 55 \\
\hline 5 & 1.3 & 1.4 & 1.0 & 62 & 46 & 50 \\
\hline 6 & 0.6 & 0.7 & 0.4 & 38 & 27 & 30 \\
\hline
\end{tabular}




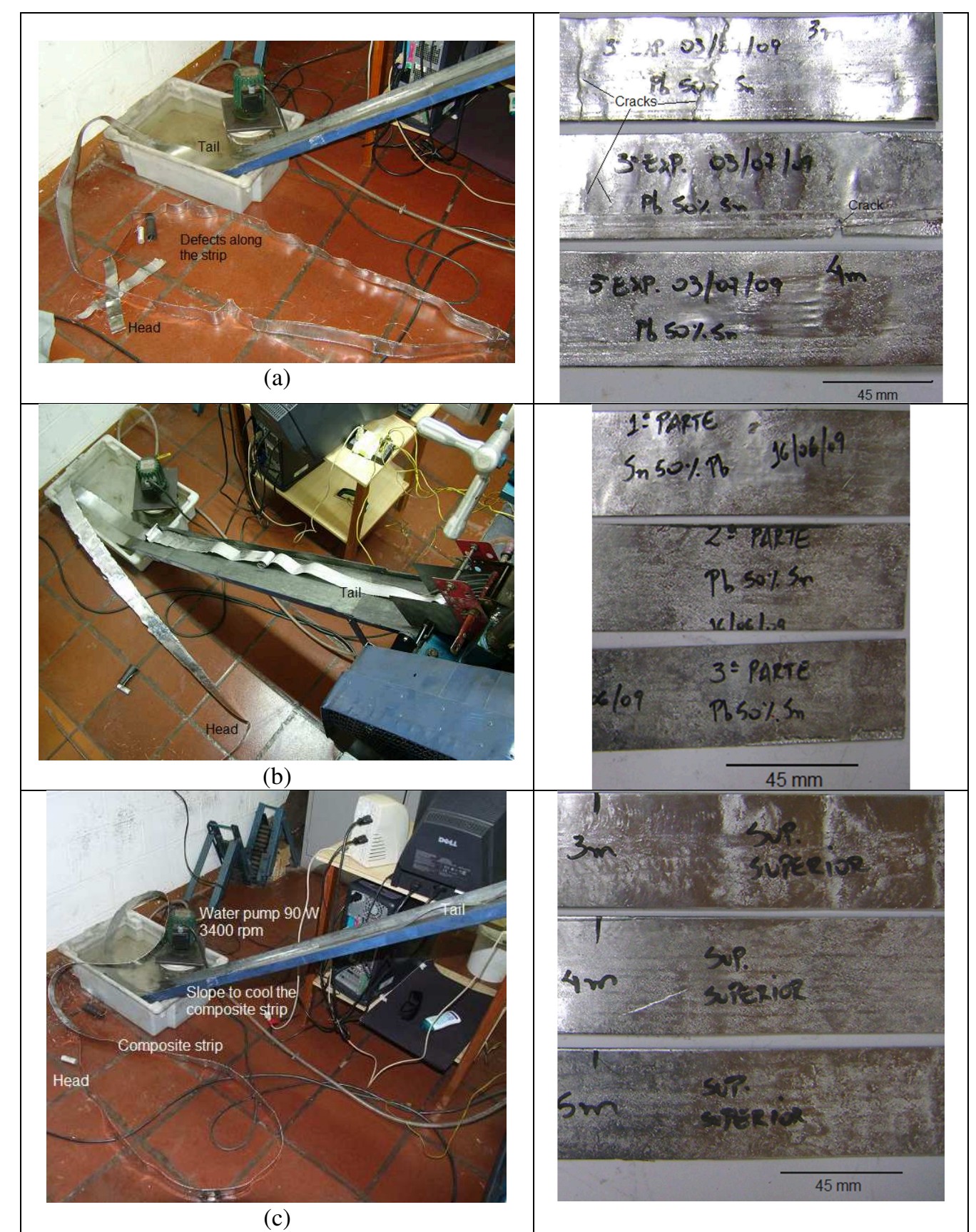

Fig. 4 MMCS-ing produced at different pouring temperatures that illustrate the defects along the strip: (a) $\approx 270{ }^{\circ} \mathrm{C}$ - cracks and chipped edge along the strip; (b) $\approx 280{ }^{\circ} \mathrm{C}$ and (c) $\approx 290{ }^{\circ} \mathrm{C}$.

The effect of the pouring temperature is clearly shown in Figs. 4 (a), (b) and (c). The data suggest that the low pouring temperature of the molten alloy has limited metallic mush ductility for forming the composite, causing the metal matrix composite strip to break in several parts at the beginning of the process, as shown in Fig. 4 (a). The strip fracture is decreased at the end of processing due to the natural increase of the solidification roll temperature to approximately $50{ }^{\circ} \mathrm{C}$ [2]. It is this roll heating that could correspond to the increase in the superheating of a small quantity of the molten alloy.

Overall, the formation and consolidation of the metal matrix composite strip can be analysed simply as two dependent events. First, the wires began to embed in the strip after running $658 \mathrm{~mm}$ in approximately 4 seconds, which is the time required to feed the nozzle from the cooling slope and form the semisolid puddle. The final stage of embedment occurred after the metal strip ran approximately $5300 \mathrm{~mm}$. It seems that the upper roll squeezed the semisolid mushy puddle and consolidates the wires against the chill shell layer (see Fig. 5 in the final stage). At this point, there 
was no longer sufficient material in the nozzle to form the semisolid material puddle required to pull the wires, as shown in Fig. 5.

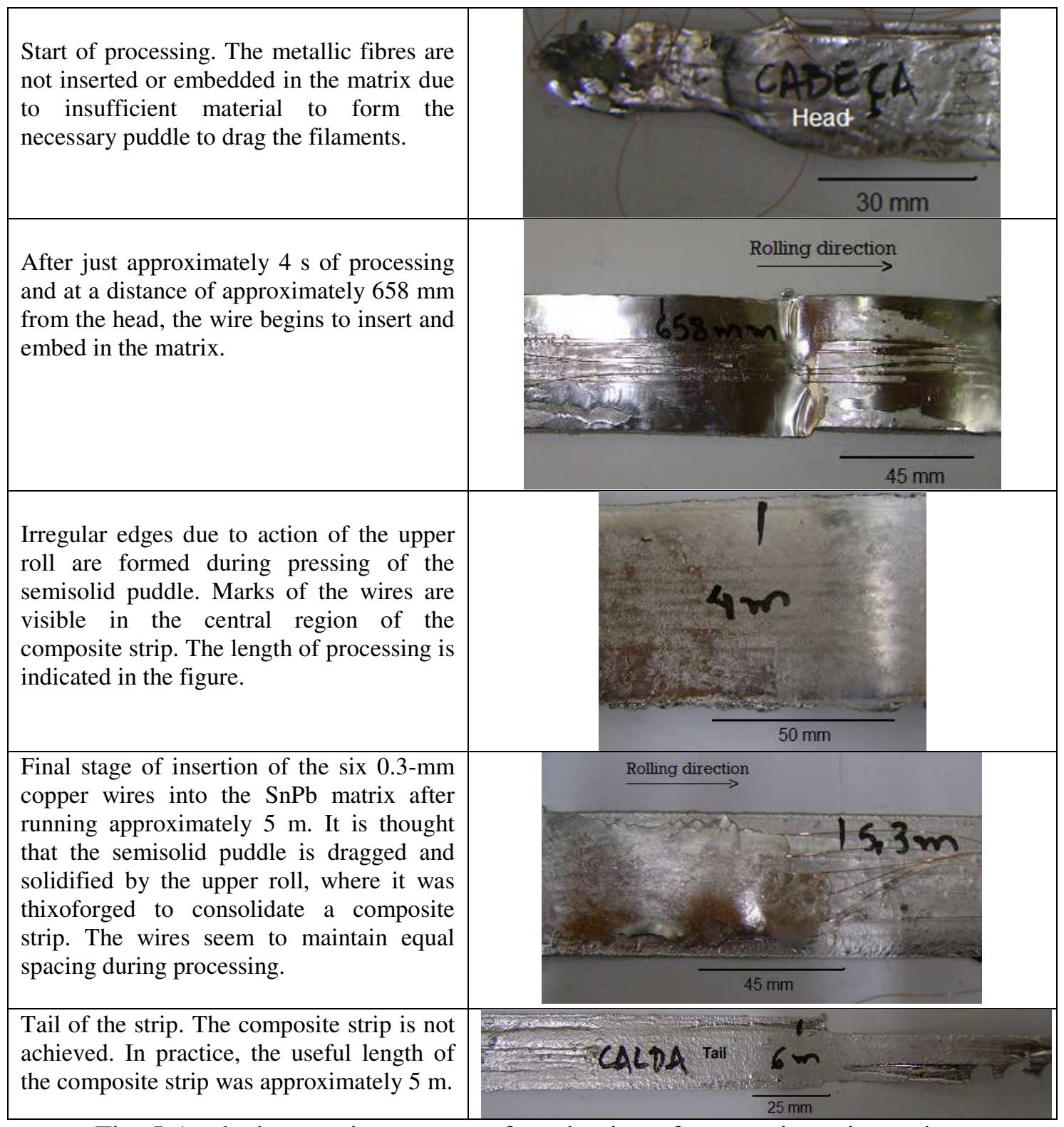

Fig. 5 Analysis at various stages of production of composite strip casting.

\section{Transversal Macroscopic Analysis and Reinforcement Distribution}

Fig. 6 illustrates the effect of TRMD-ing on the wire distribution for three experiments (1), (2) and (3) at $\approx 290{ }^{\circ} \mathrm{C}, \approx 280{ }^{\circ} \mathrm{C}$ and $\approx 270{ }^{\circ} \mathrm{C}$, respectively, which were intended to produce better insertion and embedment of the wire in the middle of strip; see Fig. 2 (a). The third experiment shows that the copper wires are better centralised in relation to the strip thickness due to the fine adjustment of the wire position at the slag weir acting as a filament guide. Here, each wire goes through the filament guide at two-hole intervals. This adjustment was performed manually, which inevitably led to the distance between wires not being accurately controlled. As a result, the six copper wires are not uniformly spaced through the cross-section.

Rapid solidification of the composite strip trapped bubbles of gas in its cross-section. The following assumptions could explain the formation and occlusions of bubbles: 1 . the movement of the wires through semisolid puddle caused turbulence, dragging air to the interior of the strip; 2 . the wire surface was contaminated with an oil film originating from the wire drawing process; 3 . The humidity of the pouring system (tundish and cooling slope); and 4. negative pressure ("ram effect", i.e., suction stroke) occurred when the filament crossed the metallic puddle. 


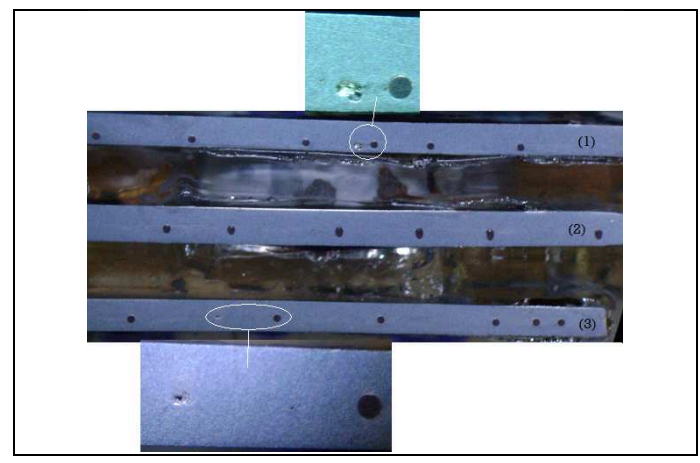

Fig. 6 Optical macroscopic examinations. Cross section of the three (1, 2, 3) MMCS-ing samples manufactured. Defects in the matrix are shown. The metallic fibres are $0.3 \mathrm{~mm}$ in diameter.

\section{Structural Analysis by Displacement of the Matrix Phases ( $\alpha$ and $\beta$ )}

In spite of the relatively small strip thickness (approximately $1.4 \mathrm{~mm}$ ) of the solidified metal matrix composite in comparison with cast products, the segregation phase along the thickness occurred with dispersion of the present phases ( $\alpha$ (bright contrast) and $\beta$, rich in lead and tin (grey contrast)), as shown in Fig. 7.

No de-bonding or interface cracks were observed between the composite constituents. Intermediate stage: $\alpha$ phase (bright) and coppers wires (dark) sandwiched by large areas $\beta$ phase (grey) layers. $\beta$ (grey contrast) nucleated at the interface of the rolls in preference to the $\alpha$ phase (white contrast). In fact, the $\mathrm{SnPb}$ alloy used is lightly hypereutectic $64.3 \mathrm{wt} \% \mathrm{Sn}$, i.e., above 61.9 wt $\% \mathrm{Sn}$ (eutectic point), causing $\beta$ phase nucleation. Absence of any products of interfacial reactions. Consequently, a good interaction between the wires/matrix occurred. The presence of carbon in the $\alpha$ phase rich in $\mathrm{Pb}$ (dark dots). This carbon content suggests that this contamination came from the crucible, the nozzle and the cooling slope, which were painted with colloidal graphite [3]. As solidification progressed from the outer surfaces to the middle body of the strip, there was a tendency to form $\beta$ globules surrounded by $\alpha$ phase. This behaviour suggests that the degenerating columnar structure has the tendency to emit $\beta$ globules into the semisolid material slurry retained in the nozzle.

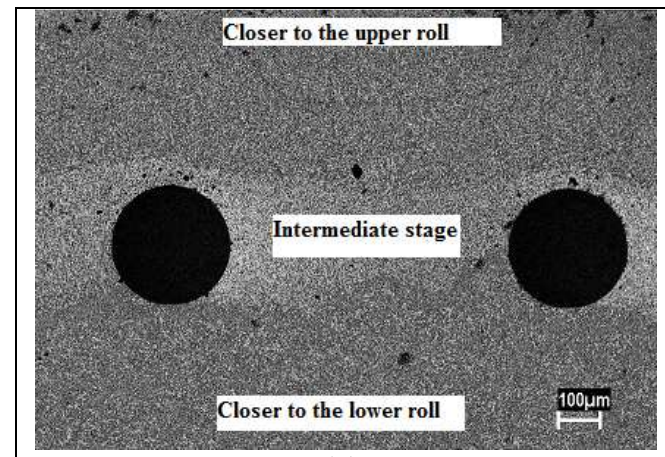

(a)

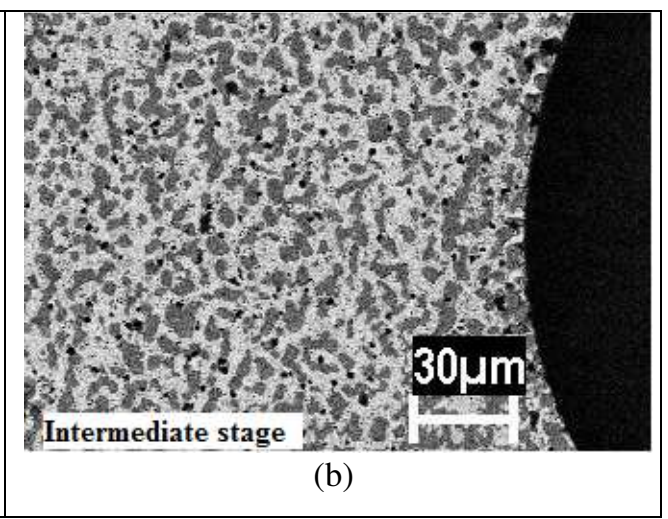

(b)

Fig. 7 Backscattered SEM images of the solidification structures from a continuous metal matrix composite strip casting reinforced with $0.3-\mathrm{mm}$ copper wires in a $\mathrm{SnPb}$ eutectic matrix (a) and absence of any products of interfacial reactions (b). Copper wires shown in dark contrast.

\section{Mechanical Behaviour Analysis}

Fig. 8 shows a tensile test curve for the TRMD-ed composite made from six 0.3-mm copper wires inserted in a $\mathrm{SnPb}$ eutectic matrix and spaced at intervals of one stainless steel cloth perforation at the slag weir, resulting in a volumetric fraction of approximately $1.4 \%$. In this figure, the SEM of the fracture surfaces reemphasises the ductile fracture of the composite constituents and the defects in the matrix. Serrations, typical of interfacial friction, are indicated by the curve. This observed serration may be caused by interfacial friction between the fibre and the matrix. 


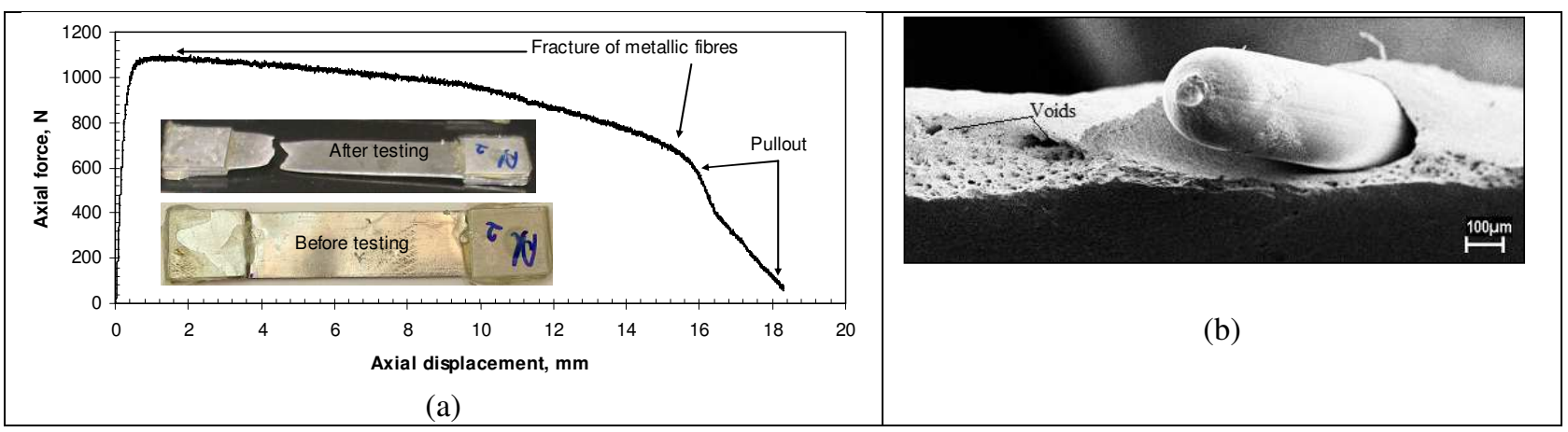

Fig. 8 A tensile test curve for six 0.3-mm diameter copper wires in a SnPb eutectic alloy (a); and SEM fractograph of a tensile test specimen (b).

Fig. 9 shows the experimental data collected in this work compared with the ROM (Rule of Mixtures) curve, where: $V_{f} \approx 1.4 \%$ and $\sigma_{\mathrm{c}} \approx 33 \pm 4 \mathrm{MPa}$. The theoretical minimum fibre volume $\left(\left(V_{f}\right)_{\min }\right)$; and the theoretical critical fibre volume $\left(\left(V_{f}\right)_{\text {crit }} \approx 2.0 \%\right)$ were above $\mathrm{V}_{\mathrm{f}} \approx 1.4 \%$; as a result, the composite strength property $\left(\sigma_{\mathrm{c}} \approx 33 \pm 4 \mathrm{MPa}\right)$ did not exceeded the matrix strength. In fact, $\sigma$ $\sigma_{\mathrm{m}}^{\text {us }}=42 \mathrm{MPa}, \sigma_{\mathrm{f}}^{\text {us }}=479 \mathrm{MPa}$ and $\sigma_{\mathrm{m}}^{\prime}=33 \mathrm{MPa}$ represent the maximum tensile stress of the matrix, the maximum tensile stress of the copper wire, and the flow stress of the matrix, respectively [6].

Minimum fibre volume
$\left(V_{f}\right)_{\min }=\frac{\sigma_{m}^{u t s}-\sigma_{m}^{\prime}}{\sigma_{f}^{u t s}+\sigma_{m}^{u t s}-\sigma_{m}^{\prime}} \approx 1.8 \%$ and $\left(\sigma_{\mathrm{c}}\right)_{\min } \approx 42 M P a$
Critical fibre volume

Fig. 9 A comparison of the experimental data and the rule of mixtures curves, as indicated. The theoretical projection of the wire stacking I (a); II (a/b); and III (a/b/a) to increase the ultimate tensile strength (UTS) of the composite strips are indicated for future work.

\section{Summary}

A multifilament of copper wire was totally embedded in the matrix and well-aligned. In this study, the compliance of the copper wires did not provoke cracks at the reinforcement/matrix interface. Fine solidification structures in the matrix were changing, and the gas bubbles formed were carried along in the matrix. Low volume fractions resulted in a lower UTS matrix strength. It is possible, using this equipment, to increase the mechanical properties by inserting more filaments. The ability to insert fibres into the metallic matrix both continuously and linearly will make it possible to obtain MMCs with anisotropic properties, which will have a strong impact in mechanical, electronic and magnetic applications.

\section{Acknowledgments}

We are grateful to FAPESP (2008/03572-7) - São Paulo (S.P.) of Brazil, to Mr. Lourenço Nampo of Cookson Electronics Brasil Ltda for providing the $\mathrm{SnPb}$ alloy and to Dr. Mirabel Cerqueira Rezende, Dr. Dalcy Roberto dos Santos, Dr. Carlos Alberto Alves Cairo and Sgt. Rogério Duque Gonçalves from the Institute of Aeronautics and Space Materials Division (DCTA/IAEAMR) for their cooperation in providing the SEM images, microanalyses and DSC data. 


\section{References}

[1] T. Haga, K. Takahashi, H. Inui, H. Sakagushi, S. Watari, S. Kumai, Roll casting of wire inserted aluminum alloy strip, J. Mater. Process. Technol. 187-188 (2007) 508-511.

[2] T. Haga, K. Takahashi, H. Watari, S. Kumai, : Casting of wire-inserted composite aluminum alloy strip using a twin roll caster, J. Mater. Process. Technol. 192-193 (2007) 108-113.

[3] A.D. Lima Filho, R. S. Ikeda, Continuous production of metal matrix composites from the semisolid state. . Solid State Phenom. 192-193 (2012) 83-88.

[4] T. Haga, Semisolid strip casting using a twin roll caster equipped with a cooling slope, J. Mater. Process. Technol. 130-131(2002) 558-561.

[5] A.D. Lima Filho, M.I. Yamasaki, L.A. Ono, L. Nampo, A. Padilha, A comparison of deep drawing and ironing of metal alloy strip produced conventionally and non-conventionally via semi solid material processing. Solid State Phenom. 141-143 (2008) 49-54.

[6] ASM Handbook, vol. 2, 10 ed., Properties and Selection: Nonferrous Alloys and Special Purpose Materials. Metals Park, ASM International, 1990.9 
Semi-Solid Processing of Alloys and Composites XIII

10.4028/www.scientific.net/SSP.217-218

Continuous Production of a Multi-Filament Reinforced Metal Matrix Composite Strip from the Semisolid State

10.4028/www.scientific.net/SSP.217-218.265

\section{DOI References}

[1] T. Haga, K. Takahashi, H. Inui, H. Sakagushi, S. Watari, S. Kumai, Roll casting of wire inserted aluminum alloy strip, J. Mater. Process. Technol. 187-188 (2007) 508-511.

10.1016/j.jmatprotec.2006.11.088 
Reproduced with permission of the copyright owner. Further reproduction prohibited without permission. 